\title{
OBTENÇÃO DE DADOS DE EQUILÍBRIO DE SISTEMAS AQUOSOS BIFÁSICOS FORMADOS POR POLIETILENOGLICOL E LÍQUIDO IÔNICO
}

\author{
O. R. R. GANDOLF ${ }^{*}$, G. R. F GONÇALVES ${ }^{1}$, J. G. PIMENTEL ${ }^{2}$, R. C. F. BONOMO ${ }^{1}$, R. C. I. \\ FONTAN $^{3}$, C. M. VELOSO ${ }^{3}$ \\ ${ }^{1}$ Universidade Estadual do Sudoeste da Bahia, Mestrando em Engenharia e Ciências de \\ Alimentos. \\ ${ }^{2}$ Universidade Estadual do Sudoeste da Bahia, Mestranda em Ciências Ambientais \\ ${ }^{3}$ Universidade Estadual do Sudoeste da Bahia, Departamento de Tecnologia Rural e Animal \\ *e-mail: olga.gandolfi@hotmail.com
}

\begin{abstract}
RESUMO
A busca crescente por processos seguros e eficazes de separação para materiais biológicos aliado as propriedades vantajosas do polietileno glicol (PEG) e líquidos iónicos (LI), levaram a aplicações promissoras e atraentes dos novos sistemas aquosos bifásicos. Diante disso, objetivou-se nesse trabalho a construção das binodais para sistemas aquosos bifásicos compostos por polietilenoglicol (PEG), líquido iônico (cloreto de 1-etil-3-metilimidazólio) e água. Os polímeros utilizados de diferentes massas molares foram PEG 1500 g.mol ${ }^{-1}$ e PEG 4000 g.mol ${ }^{-1}$. Os sistemas PEG $1500+$ líquido iônico e PEG 4000 + líquido iônico foram analisados nas temperaturas de $(20$ e 50) ${ }^{\circ} \mathrm{C}$. O efeito da temperatura nas curvas binodais foi analisado tendo em vista os dois tipos de PEG utilizados, sendo observado uma diminuição da área bifásica com o aumento da temperatura para ambos os sistemas utilizados. O efeito da massa molar também foi estudado, verificando um aumento da área bifásica nos sistemas com o PEG de maior massa molar.
\end{abstract}

\section{INTRODUÇÃO}

Em tempos de melhoria da engenharia molecular e projeção de proteínas, o desenvolvimento de novos e biocompatíveis métodos de extração, para a separação e purificação de enzimas e proteínas, vêm ganhando importância crescente. Dentre os processos existentes atualmente um método eficaz e economicamente viável, que é uma ramificação da extração líquido-líquido chamada de extração por Sistemas Aquosos Bifásicos (SAB's), vem destacando-se para a separação e purificação de biomoléculas. Este processo tem como princípio a utilização de duas fases aquosas imiscíveis que podem ser obtidas pela adição de duas soluções aquosas de dois polímeros hidrófilos naturais ou sintéticos, de uma solução polimérica e uma solução salina e pela combinação de dois sais. Portanto, a separação/purificação das biomoléculas é realizada em ambiente adequado e sob condições amenas, visto que as fases de um SAB são compostas em sua maioria de água (70\% a 90\%), o que favorece seu uso na extração de compostos de origem biológica, uma vez que favorecem a estabilidade dos mesmos (ALBERTSSON, 1986; PEREIRA et al., 2013; SELBER et al, 2001). Esta técnica é amplamente utilizada na purificação de biomoléculas, onde as suas vantagens incluem seletividade favorável, baixo custo e adaptabilidade para o processamento contínuo da amostra e retenção da atividade biológica (KRONER et al., 1978). 
SAB a base de polímeros têm sido largamente utilizados na separação e purificação de proteínas, enzimas, células do sangue e antibióticos (ALBERTSSON, 1986; ZASLAVSKY, 1995; PEREIRA et al., 2012). Entretanto, apesar de suas vantagens, SAB à base de polímeros apresentam fases com polaridades semelhantes, um fato que restringe sua aplicação, devido a baixos rendimentos de extração e/ou purificação. Já os SAB's formados por PEG e sal consiste de um grupo hidrofóbico constituída principalmente por polímeros, e uma fase hidrofílica (e iônica), compostas por sais inorgânicos de uma elevada densidade de carga (MAZZOLA et al., 2008). A gama limitada de diferenças de polaridades entre as duas fases limita assim a aplicabilidade de $\mathrm{SAB}$ à base de polímero convencional para fins de extração e/ou separação. No entanto, a substituição de um sal inorgânico de elevada densidade de carga e/ou um polímero por líquido iônico, pode fornecer um controle maior das polaridades das fases, uma vez o LI que pode ser escolhido adequadamente, tendo em conta a grande variedade de suas estruturas (PLECHKOVA e SEDDON 2008).

As diferenças limitadas entre as duas fases nestes sistemas convencionais, conduziu à procura de estratégias alternativas, tais como a derivatização do polímero ou a utilização de aditivos, a fim de melhorar os rendimentos de extração da molécula alvo (LI e KAO, 2003; ROSA et al., 2007; JIANG et al., 2009; PEREIRA et al., 2010).

Em particular, os novos sistemas aquosos bifásicos (SAB) à base de PEG-LIágua exibem uma gama hidrofóbicohidrofílico mais ampla em comparação com sistemas convencionais. Esta característica tem um impacto importante na separação, uma vez que aumenta a variedade de biomoléculas que pode ser separada ou purificado por SAB (FREIRE et al 2012; PEREIRA et al 2013).
Ao se fazer um estudo da partição é necessário conhecer os dados de equilíbrio dos sistemas que serão utilizados. Para cada sistema seja polímero/polímero, polímero/sal polímero/líquido iônico existe um diagrama de fases que define as proporções entre os componentes formadores das fases. Alguns já estão disponíveis na literatura, porém, é importante ao testar um novo sistema que se construa um diagrama nas condições de trabalho a serem utilizadas na extração (temperatura, massa molar do PEG, pH, entre outros).

Diante do exposto, objetivou-se nesse trabalho estudar o comportamento do sistema de duas fases constituídos por líquido iônico (cloreto de 1-etil-3-metilimidazólio) e polietilenoglicol (1500 g. mol ${ }^{-1}$ e 4000 g.mol $\left.{ }^{1}\right)$ e água nas temperaturas de $20^{\circ} \mathrm{C}$ e $50^{\circ} \mathrm{C}$.

\section{MATERIAIS E MÉTODOS}

\subsection{Materiais}

O trabalho experimental foi realizado no Laboratório de Engenharia de Processos da Universidade Estadual do Sudoeste da Bahia, campus de Itapetinga. Os reagentes utilizados na condução deste trabalho foram: cloreto de 1-etil-3-metilimidazólio $\quad([\mathrm{C} 2 \mathrm{~min}] \mathrm{Cl}) \quad$ da Sigma-Aldrich (USA) com grau de pureza $\geq$ 95\% e polietilenoglicol 1500 g.mol ${ }^{-1}$ e 4000 g.mol ${ }^{-1}$ da Synth, Brasil.

Nos experimentos foram empregados água destilada e todos os reagentes usados foram de grau analítico.

\subsection{Métodos}

\subsubsection{Preparo Dos Sistemas Aquosos Bifásicos}

Para montagem do sistema aquoso bifásico, composto por PEG-LI-água, serão preparadas soluções estoque de PEG em água e LI em água. 
Os diagramas de fase dos sistemas aquosos foram formados utilizando soluções aquosas de PEG 1500 + LI + água, PEG 4000 $+\mathrm{LI}+$ água, nas temperaturas de $20^{\circ} \mathrm{C}$ e $50^{\circ} \mathrm{C}$. Esses sistemas serão construídos pela aplicação do método turbimétrico (ALBERTSSON, 1986), que indica o início da região bifásica. $O$ procedimento consiste em pesar $1 \mathrm{~g}$ da solução de PEG em tubos de vidro, para melhor visualização da turvação. O tubo contendo a solução de PEG será levado ao banho termostático e deixado até atingir o equilíbrio térmico. Em seguida, serão adicionadas gota a gota da solução de LI $(50 \mu \mathrm{L})$ com auxílio de uma pipeta automática, até ocorrer à turvação do sistema (solução bifásica). Nesse momento deverá ser registrada a quantidade de LI que provocou a turvação. Em seguida, o sistema deverá ser titulado com água destilada até o desaparecimento da turvação, registrando o seu valor. Esse procedimento deverá ser repetido continuamente até a obtenção dos pontos necessários para fazer a curva.

A equação empírica (Equação 1) foi utilizada para correlacionar os dados das binodais (WANG et al., 2010).

$\mathrm{w}_{1}=\exp \left(\mathrm{a}+\mathrm{b} \mathrm{w}_{2}{ }^{0,5}+\mathrm{cw}_{2}+\mathrm{dw}_{2}{ }^{2}\right)$

Onde w1 é a fração mássica de polietilenoglicol, w2 é a fração mássica de líquido iônico e a, b, c e d são parâmetros de ajuste da equação.

\section{RESULTADOS}

Foram realizados os estudos do efeito da temperatura e massa molar dos polímeros com a construção das curvas binodais.

\subsection{Efeito da Temperatura nos Diagramas Estudados}

Com o aumento da temperatura as curvas de equilíbrio tendem a se deslocarem para as regiões próximas aos eixos, em sistemas mais tradicionais. Mas foi observado no sistema composto por PEG e LI que ao se aumentar a temperatura tanto para o PEG 1500 g.mol ${ }^{-1}$ quanto para o PEG 4000 g.mol ${ }^{-1}$ ocorreu justamente o contrário, como pode ser observado nas figuras 1 e 2 .

Figura 1 - Diagramas de equilíbrio de fases para sistemas PEG 1500, LI e água nas temperaturas de $20^{\circ} \mathrm{C}$ e $50^{\circ} \mathrm{C}$.

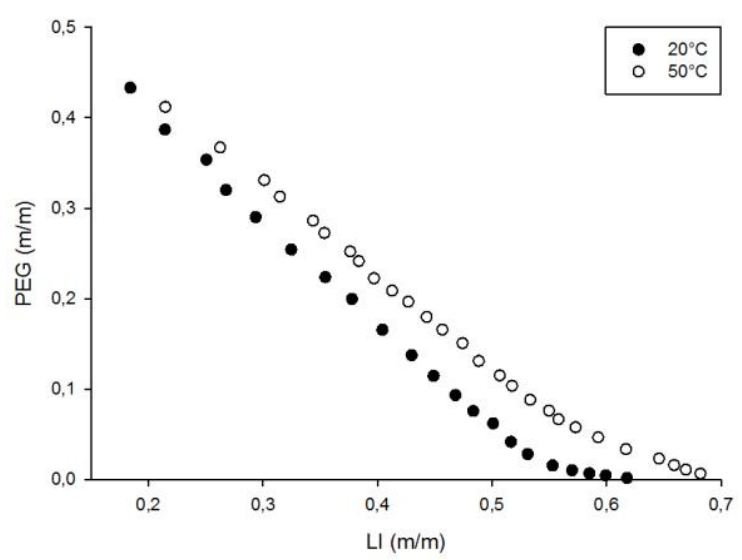

Fonte: Dados da pesquisa.

Figura 2 - Diagramas de equilíbrio de fases para sistemas PEG 4000, LI e água nas temperaturas de $20^{\circ} \mathrm{C}$ e $50^{\circ} \mathrm{C}$.

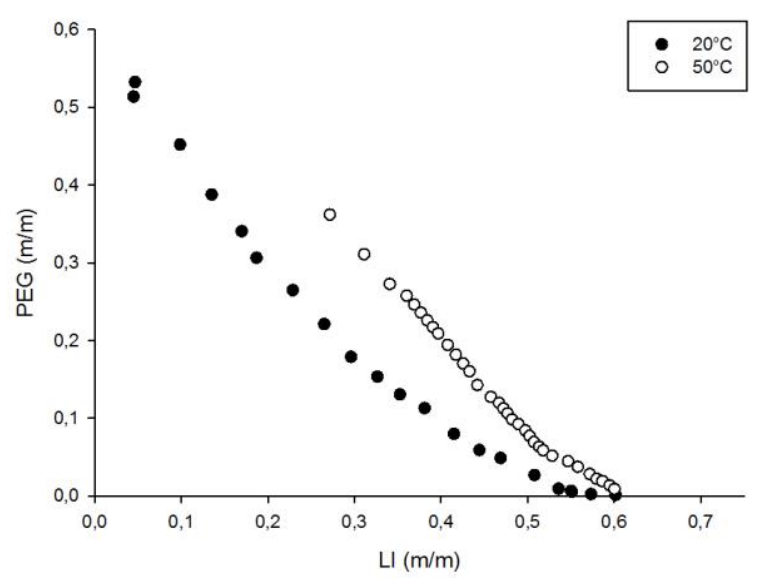

Fonte: Dados da pesquisa.

Com o aumento da temperatura foi verificado uma diminuição da região bifásica. Esse comportamento está de acordo aos 
encontrado por Freire et al., (2012) que estudaram as interações que controlam o comportamento de fases compostas de PEG e LI. Esse comportamento também foi observado nos SAB compostos por líquido iônico e sais inorgânicos (DU et al., 2007; CHEN et al., 2010) e aos sistemas compostos por polímeros/polímero. Tal comportamento pode ser resultado da baixa densidade de carga dos líquidos iônicos em relação aos sais inorgânicos.

\subsection{Efeito da Massa Molar do PEG nos Diagramas Estudados}

Ao se comparar os sistemas na mesma temperatura $\left(20^{\circ} \mathrm{C}\right.$ ou $\left.50^{\circ} \mathrm{C}\right)$ e variando a massa molar do polímero (PEG 1500 g.mol ${ }^{-1}$ e PEG 4000 g.mol ${ }^{-1}$ ) como observado na figura $3\left(20^{\circ} \mathrm{C}\right)$ e na figura $4\left(50^{\circ} \mathrm{C}\right)$ pode-se observar que o PEG de maior massa molar apresentou uma maior região bifásica. Uma tendência semelhante foi observado no SAB convencional formados por PEG e sal inorgânico, a hidrofobicidade aumenta com o aumento do peso molecular do PEG, facilitando assim a formação do SAB. PEG de maior peso molecular, apresentam uma menor afinidade com a água.

Figura 3 - Diagramas de equilíbrio de fases para sistemas PEG 1500 e PEG 4000, LI e água na temperatura de $20^{\circ} \mathrm{C}$.

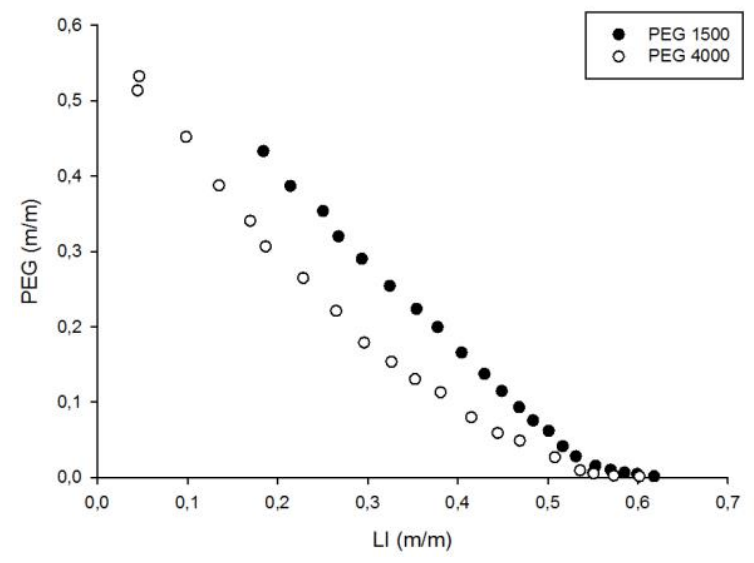

Fonte: Dados da pesquisa.
Figura 4 - Diagramas de equilíbrio de fases para sistemas PEG 1500 e PEG 4000, LI e água na temperatura de $50^{\circ} \mathrm{C}$.

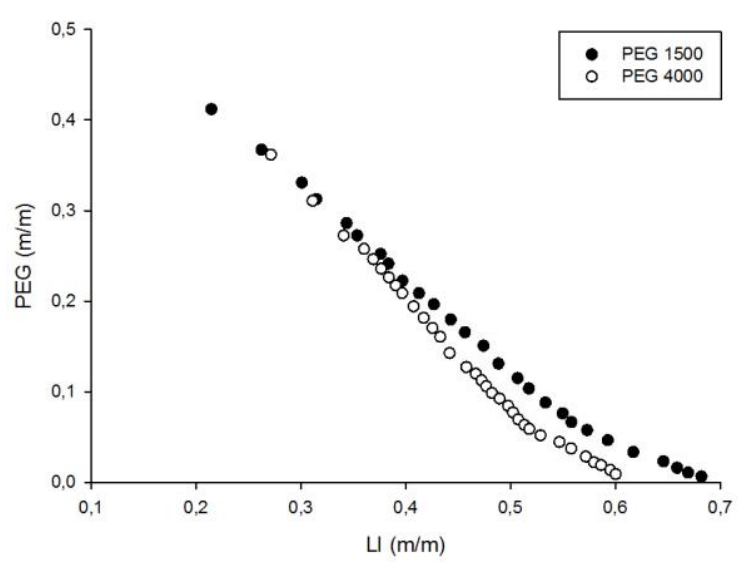

Fonte: Dados da pesquisa.

Rodriguez et al. (2009) demostraram que um aumento no peso molecular do polímero leva a intervalos maiores de imiscibilidade com líquido iônicos a base de cloreto. Por isso, polímeros com maior peso molecular são menos solúveis em líquido iônico e são mais facilmente separadas do meio aquoso.

\subsection{Parâmetros Ajustados}

Os valores obtidos para os parâmetros a, $\mathrm{b}$, c e d da equação com seus respectivos desvios padrões e os coeficientes de determinação $\mathrm{R}^{2}$ das equações ajustadas para os sistemas investigados estão presentados na Tabela 1.

Tabela 1 - Parâmetros ajustados e coeficiente de determinação $\left(\mathrm{R}^{2}\right)$ obtidos para o sistema LI-PEG pela equação de Hu et al., (2003)

\begin{tabular}{ccccc}
\hline & \multicolumn{2}{c}{$\mathbf{2 0}^{\circ} \mathbf{C}$} & \multicolumn{2}{c}{$\mathbf{5 0}^{\circ} \mathbf{C}$} \\
\cline { 2 - 5 } & $\mathbf{1 5 0 0}$ & $\mathbf{4 0 0 0}$ & $\mathbf{1 5 0 0}$ & $\mathbf{4 0 0 0}$ \\
\cline { 2 - 5 } $\mathbf{a}$ & 10,8807 & $-0,1163$ & 6,1181 & 20,0748 \\
$\mathbf{b}$ & $-58,9651$ & $-3,3229$ & $-33,4127$ & $-97,4960$ \\
$\mathbf{c}$ & 84,2775 & 4,7119 & 46,1071 & 129,3333 \\
$\mathbf{d}$ & $-56,7159$ & $-13,3305$ & $-30,7208$ & $-73,3310$ \\
$\mathbf{R}^{2}$ & 0,9979 & 0,9978 & 0,9992 & 0,9992 \\
\hline \multicolumn{2}{l}{ Fonte: Dados da pesquisa. } & &
\end{tabular}




\section{CONCLUSÃO}

Foi possível a construção das binodais para sistemas aquosos bifásicos compostos por polietilenoglicol (PEG), líquido iônico (cloreto de 1-etil-3-metilimidazólio) e água. Constatou-se que o aumento da temperatura favoreceu uma diminuição da região bifásica, e que o aumento da massa molar polietileno glicol favoreceu um aumento da região bifásica.

\section{NOMENCLATURA}

PEG - polietilenoglicol;

LI - líquido iônico;

SAB - sistema aquoso bifásico;

$\mathrm{W}_{1}$ - fração mássica de polietilenoglicol;

$\mathrm{w}_{2}$ - fração mássica de líquido iônico;

a, b, c e d - parâmetros de ajuste da equação.

\section{REFERÊNCIAS}

\section{ALBERTSSON, P.A. Partition of cell and macromolecules. New York: John Wiley, 1986, 346p.}

DU, Z.; YU, Y. L.; WANG, J. H. Extraction of proteins from biological fluids by use of an ionic liquid/aqueous two-phase system. Chem.-Eur. J., v. 13, p. 2130-2137, 2007.

CHEN, Y.; MENG, Y.; ZHANG, S.; ZHANG, Y.; LIU, X.; YANG, J. Liquid liquid equilibria of aqueous biphasic systems composed of 1-butyl-3-methyl imidazolium tetrafluoroborate + sucrose/maltose + water. J. Chem. Eng. Data. v.55, p.36123616, 2010.

FREIRE, M. G.; CLÁUDIO, A. F. M.; ARAÚJO, J. M. M.; COUTINHO, J. A. P.; MARRUCHO, I. M.; CANONGIA LOPES, J. N.; REBELO, L. P. N. Aqueous Biphasic Systems: A boost brought about by using ionic liquids, Chem. Soc. Rev. v.41, p.49664995, 2012.

JIANG, Y.; XIA, H.; YU, J.; GUO, C.; LIU, $\mathrm{H}$. Hydrophobic ionic liquids-assisted polymer recovery during penicilina extraction in aqueous two-phase system. Chemical Engineering Journal. v. 147, p.22-26, 2009.

KRONER, K. R.; HUSTEDT, H.; GRANDA, S.; KULA, M. R. Technical aspects of separation using aqueous twi-phase systems in enzyme isolation process. Biotechnol. Bioeng. v.104, p. 217-239, 1978.

LI, J. and KAO, W. J., Synthesis of polyethylene glycol (PEG) derivatives and PEGylated-peptide biopolymer conjugates. Biomacromolecules, v.4, p.1055-1067, 2003.

MAZZOLA, P. G.; LOPES, A. M.; HASMANN, F. A.; JOZALA, A. F.; PENNA, T. C. V.; MAGALHAES, P. O.; RANGELYAGUI, C. O.; PESSOA, A. Liquid-liquid extraction of biomolecules: an overview and update of the main techniques J. Chem. Technol. Biot., v. 83, p.143-157, 2008.

PEREIRA, J. F. B.; LIMA, A. S.; FREIRE, M. G.; COUTINHO, J. A. P. Ionic liquids as adjuvants for the tailored extraction of biomolecules in aqueous biphasic systems. Green Chemistry, v.12, p. 1661-1669, 2010.

PEREIRA, J. F. B.; SANTOS, V. C.; JOHANSSON, H. O.; TEIXEIRA, J. A.C.; PESSOA, A. A stable liquid-liquid extraction system for clavulanic acid using polymerbased aqueous two-phase systems. Separation and Purification Tecnology. v. 98, p.441-450, 2012.

PEREIRA, J. F. B.; VENTURA, S. O. M.; SILVA, F. A.; SHAHRIARI, S.; FREIRE, M. G.; COUTINHO, J. A. P. Aqueous biphasic systems composed of ionic liquid and 
polymers: A platform for the purification of biomolecules. v. 113, p.83-89, 2013.

PLECHKOVA, N. V.; SEDDON, K. R. Applications of ionic liquids in the chemical industry Chem. Soc. Rev. v.37, p.123150,2008 .

ROSA, P. A. J., AZEVEDO, A. M., AIRESBARROS, M. R., Application of central composite design to the optimisation of aqueous two-phase extraction of human antibodies, J. Chromatogr. A, v.1141, p. 5060, 2007.

RODRIGUEZ, H.; FRANCISCO, M.; RAHMAN, M.; SUN N.; ROGERS, R. D. Biphasic liquid mixtures of ionic liquids and polyethylene glycols. Physical Chemistry Chemical Physics v. 11, p. 10916-1092, 2009.

SELBER, K.; COLLEN, A.; HYYTIA, T.; PENTTILA, M.; TJERNELD, F.; KULA, MR. Parameters influencing protein extraction for whole broths in detergent based aqueous twophase systems. Bioseparation, v.10, p.229-236, 2001.

ZASLAVSKY, B. Y. Aqueous Two-Phase Partitioning, Marcel Dekker Incorporated, New York, 1995. 